\title{
The Moderating Effects of Emotions on Cognitive Skills
}

\author{
Mark Loon \& Robin Bell \\ (mloonkc@gmail.com) \\ Journal of Further and Higher Education (2018), Vol. 42, No. 5, pp. 694-707. \\ http://dx.doi.org/10.1080/0309877X.2017.1311992
}

\begin{abstract}
An important challenge in higher education today is the growing tutor-student ratio that diminishes the 'human touch'. As learning and teaching is ultimately an interpersonal process, this will lead to student discontent and impact on their learning. Whilst there is little that teaching practitioners can do in terms of the growing student numbers they have to tutor, they may influence student learning by enhancing their positive emotions. This study examines the importance of emotions in improving cognitive skills and how they interact with knowledge and reflection. This research contributes to theory by examining the role of emotions as a moderating factor in the learning process. Our findings reveal that emotions moderate the direct relationship between knowledge and cognitive skills, and the indirect relationship between knowledge and cognitive skills via reflection. The findings demonstrate the critical role that emotions play in student learning. Implications for theory and practice are discussed.
\end{abstract}

\section{Keywords}

Emotions, cognitive skills, knowledge, reflection, simulation games 


\section{Introduction}

Teaching in higher education is an evolving challenge. As education becomes more accessible, student numbers continue to grow whilst resources and time allocated to tutors generally remain the same. Such challenges are well established as the Financial Sustainability Strategy Group (FSSG; 2015), which is part of the Higher Education Funding Council for England (HEFCE), states that growing staff-student ratios reduce contact time, which inevitably contributes to decreasing student satisfaction. These challenges are a global phenomenon, as the Organisation for Economic Cooperation and Development (OECD) also adds that the situation is exacerbated by increasing tuition fees that has shifted students' views in considering themselves as customers and thus are more demanding (Hénard and Leprince-Ringuet 2008). As tutor-student ratios increase so do teaching loads. Heavy teaching schedules ultimately result in a shift away from a learner-centred approach to the content-centred approach as tutors may feel the pressure to ensure that all materials are covered in time (Hénard and Roseveare 2012).

The growing challenges of teaching in higher education mean that the prospect of the 'human touch' being diminished will be inevitable. Whilst this is not a problem per se, learning and teaching is inescapably an interpersonal process. Hence as tutors increase focus on content, students will start to feel estranged from the learning process and are more likely to become dissatisfied (Goldman and Goodboy 2014, Mazer 2013a), which will negatively impact their learning. Indeed, research e.g. Trigwell, Ellis, and Han (2012), and Värlander (2008), has demonstrated that students' effective learning is partly due to how they feel and the emotions they experience. For example, positive emotions can enhance students' intrinsic motivation to learn, which leads to deep learning (Kember, Biggs, and Leung 2004). Emotions play a significant role in the development and application of logic, intuition and ideas (Rogers 1994, Rawson 2000). This is not surprising, as it has been argued that emotions explain approximately 40 percent of variance in behaviour (Biggers and Rankis 1983). Research has also shown specifically that emotions are integral to learning in terms of memory and 
motivation (Pekrun, Elliot, and Maier 2006, Ashby, Isen, and Turken 1999), directing cognitive resources (Meinhardt and Pekrun 2003), sustaining interest (Ainley, Corrigan, and Richardson 2005), triggering different modes of problem solving and information processing (Isen 1999), and selfregulation (Pekrun et al. 2002). The consideration of emotions helps to inform the design and delivery of courses that appeal to the affective aspect of students, which ultimately aids them to make significant gains in their learning. Beard, Clegg, and Smith (2007) supports such an argument as they posit that the focus on emotions facilitates transformational change in our assumptions and perspectives on learning, such as the shift from transmission to engagement, reproduction to transformation, learning space to learning climate, and subject-specific to whole person. Pekrun et al. (2002) assert that students' overall university performance is largely dependent upon their ability to self-motivate, which is essentially based on emotions.

Various scholars have found that the role emotions play in learning is multi-faceted, in particular as an outcome of learning processes e.g. Schiefele (1991) and as a predictor of learning outcomes e.g. Jennings and Greenberg (2009). However, there is still insufficient empirical evidence that shows the moderating effects of emotions in learning. Research into the moderating effects of emotions, either positive or negative, is important as it informs theory and practice of how emotions can and may interact with other learning constructs in producing positive or negative outcomes. In this study, the learning processes of acquiring knowledge and reflection have been selected as the independent variables that contribute to the development of the dependent variable of cognitive skills. These three constructs are highly ubiquitous in business management courses and their application in this study helps to enhance the ecological validity of the findings. In addition to conventional teaching methods, we use a computer-based simulation game (CSG) to stimulate positive emotions in students. Moreover, an important aspect of the research design is the context of the study that takes place in a strategic management course that epitomises the growing challenges in teaching (e.g. large student numbers) at a UK university. 
By answering the call for further research into the role of emotions on learning (Vince 2010, Ward and Shortt 2013) this study contributes to theory by identifying the extent of the impact of emotions on the development of cognitive skills. This study also contributes to practice by informing teaching professionals of the benefits in using technology in stimulating positive emotions that facilitate student learning, and in complementing conventional pedagogical methods. The next section contains a discussion of the constructs and presents the hypotheses. This is followed by a discussion of the research context and methods. The penultimate section contains a discussion of the findings, followed by a conclusion including an acknowledgement of the limitations of research and a discussion of potential directions for future research.

\section{Literature Review}

\section{Cognitive Skills}

In terms of intellectual development, increasing conceptual and thinking skills is a highly valued outcome. Cognitive skills pertain to reasoning, which is is fundamentally going beyond the given information (Bruner 1957). Carroll (1993) argues that there are three types of reasoning; deductive, inductive and quantitative. Deductive reasoning is logically inferring a conclusion from two premises, whilst inductive reasoning is estimating an outcome based on a number of evidences. Quantitative reasoning involves both deductive and inductive reasoning used in quantitative calculations. Abduction is another form of reasoning that is usually known as working backwards from observation to cause (Vertue and Haig 2008). Effective reasoning is an important cognitive skill that enables students to 'piece things' together.

Nonetheless, cognitive skills are more than just plugging the gaps when information is absent.

Cognitive skills are higher-order thinking skills that enable individuals to perform complex tasks (Van Lehn 1996) such as critical thinking, problem solving and decision making. Dewey (1933) posit that critical thinking concerns suspending judgement and possessing a healthy degree of scepticism. 
Critical thinking is a broad construct that also involves the cognitive processes of evaluation and synthesis (Giancarlo and Facione 2001). The American Philosophical Association (1990), in addition, argues that critical thinking is purposeful and involves self-regulation.

Problem solving is inherently an intellectual exercise (Frensch and Funke 2002) involving framing (Quesada, Kintsch, and Gomez 2005) and formulating (DeYoung, Flanders, and Peterson 2008) a problem in an effective manner, followed by the development of a sustainable solution (Ackoff 1993). Effective problem solving fundamentally involves decision making throughout the process. Tallman and Gray (1990) argue that decision making essentially involves identifying and evaluating of choices.

Gaining cognitive skills such as critical thinking, problem solving and decision making is crucial in strategic management as it prepares students to be able to deal with the ambiguity and uncertainty that characterise today's business world. Obtaining a university degree is about being an independent thinker who is able to know how to address issues, know how to use available resource, and understand the merits and limits of their decisions. Effective cognitive skills enable students to make optimum trade-offs when ideal solutions are not possible.

\section{Knowledge}

Acquiring knowledge is a key process in university. Students acquire knowledge through various means, including reading textbooks, attending lectures and discussing matters with classmates. In addition, there are different degrees of knowledge attainment such as memorisation, comprehension and application. Extant literature highlights two distinct forms of knowledge: conceptual knowledge and procedural knowledge (Muijs and Lindsay 2008, Rittle-Johnson and Star 2009). Conceptual knowledge is considered the higher-order form of knowledge in which learners are able to recognise and explain the key characteristics of concepts and distinguish them from 
other concepts (Fyfe, Rittle-Johnson, and DeCaro 2012). For example, in the context of strategic management, strategies that organisations develop are almost entirely dependent on the conditions of the external environment and circumstances of the organisation. A student who has mastered the concept of strategic management will be cognisant of these environment and situational differences, and how this influences the type of strategies employed.

Procedural knowledge, in contrast, is knowing 'how' (Byrnes 1992) and involves knowing the sequence of actions required to complete a task or solve problem (Rittle-Johnson and Alibali 1999). Hallett, Nunes, and Bryant (2010) state that procedural knowledge involves a series of goal-directed action sequences that can be enacted independent of meaning. Generally, most scholars and practitioners accept that conceptual knowledge must be learned before procedural knowledge, as the latter is only effective if the concept has been understood (Hallett, Nunes, and Bryant 2010). For example, understanding the purpose and principles of strategy frameworks and models not only helps in their application but also help students to better interpret implications of the results.

Anderson and Krathwohl (2001) extended this dual view of knowledge, arguing that metacognitive knowledge is also a higher-order construct encompassing knowledge about self and context. Metacognitive knowledge is not only relevant to real-life strategist in the corporate world but also students. In any strategy development exercise, it is almost assured that any set of information used in strategy development will be incomplete and opaque, thus students' mindfulness of such potential limitations helps in the better development of prudent and practical strategies.

\section{Reflection}

Schön (1983) posits that reflection is the process of learning from sense making. Wood Daudelin (1997) makes the link between learning and reflection when she states: 
'reflection is the process of stepping back from an experience to ponder, carefully and persistently, its meaning to the self through the development of inferences; learning is the creation of meaning from past or current events that serves as a guide for future behaviour' ( $\mathrm{p}$. 39).

Effective reflection has a significant effect on cognitive development as Scott (2010) argues that reflection raises one's consciousness and mastery of one's own thinking. The outcome of reflection is similar to the effect of Bateson's (1972) third-order learning, and Argyris and Schon's (1996) double loop learning, whereby individuals are able correct themselves in their learning and thus become more adept and effective learners.

The reflection process involves contemplation (Zundel 2013, Pedrosa-de-Jesus and Watts 2014), introspection (Zuckerman 2004, Raelin 2007), thoughtfulness (Leijen et al. 2012) and mindfulness (Keevers and Treleaven 2011). Ultimately, reflection develops self-awareness and self-management (Petriglieri, Wood, and Petriglieri 2011). Reflection is associated with the development of metacognitive skills (Peterson 1995, Knight 2002), which involves understanding how individuals think, construct knowledge, and employ strategies for action such as problem solving. This is supported by Nielsen (2008) who explains that reflection enhances learning by enabling students to better 'frame' problems from different perspectives.

Reflection also helps with the transferability of skills as reflection enables learners to be aware of what they have learnt and how it can be applied in different contexts (Georghiades 2000). For example, reflection may help students to understand how some organisational strategies may be effective in some situations for some organisations but not for others. Whilst this can be learned as explicit knowledge, it is impossible for any curriculum to cover all situational factors, thus effective reflection may help students to transfer what has been learned to different contexts. 


\section{Emotions}

Shipton and Sillince (2012) define emotion is as a 'felt phenomena arising from the appraisal of a situation and shaping action readiness' (p. 495). There are two related theoretical models in the study of emotions, discrete emotions (also known as the basic emotion model) and dimensional emotions (Harmon-Jones et al. 2011). The discrete emotions model, adopted for this study, is based on universal and innate basic emotions such as happiness and sadness (Ekman 1992) whilst the dimensional emotion model asserts that all affective states arise from two independent neurophysiological systems: arousal (activation-deactivation) and valence (pleasure-displeasure continuum) (Posner, Russell, and Peterson 2005). The most prevalent types of emotions in the discrete model in many learning environments are interest, engagement (Mazer 2013b) and appreciation (Pekrun et al. 2002), as well as negative emotions such as boredom, anxiety and/ or fear. For example, affective states in learning such as interest and curiosity may be triggered when novelty is encountered (Ainley 2008), excitement and appreciation when insights are gained (Parnes 1975), delight when challenges are surmounted ( $D^{\prime}$ Mello and Graesser 2011), and engagement when learners feel appropriately challenged (Csikszentmihalyi 1990).

Emotions impact learners' intellectual processes and cognitive efficiency (Shepherd 2004, Rawson 2000), specifically their receptivity when acquiring knowledge, ability to make links, and the retention and retrieval of information (Schimmack and Grob 2000, Ward and Shortt 2013). For example, emotions influence students' ability to remember strategic concepts and thus in turn impact on their ability to accurately and critically apply models and frameworks. Effective reflection is also partly influenced by emotions (Hinett 2002). The tight coupling between cognition and emotion in reflection (Culpin and Scott 2012) suggests that any changes in emotions will affect learners' reflection and ultimately the development of their skills. For example, reflection requires an honest assessment of one's own knowledge. Negative emotion may cause strong biases to creep into students' reflection processes as students may favour the application of particular concepts that 
they found more appealing rather than those that are more appropriate. The following hypotheses are therefore proposed, as depicted in Figure 1.

H1: The direct relationship between knowledge and cognitive skills is moderated by emotions

H2: The indirect relationship between knowledge and cognitive skills via reflection is moderated by emotions

Figure 1: Hypothesised model

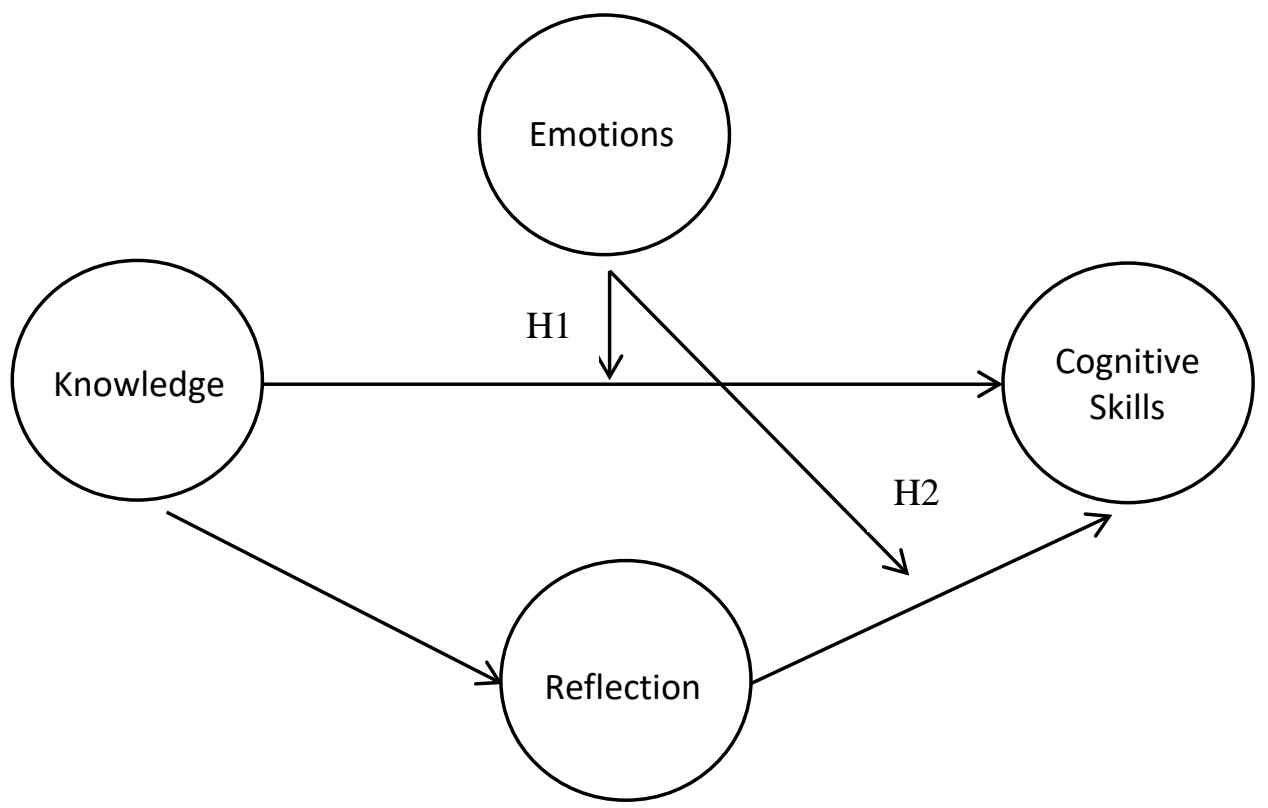

\section{Context and Method}

\section{Context}

This study is based on a year-long strategic management course involving final-year undergraduate students at a UK business school. The course included a weekly two-hour lecture followed by an hour-long seminar. A computer simulation game (CSG) was introduced during the final six weeks of the course. The CSG is based on the main textbook adopted in the course with all the business issues presented relevant to the theories, models, frameworks and principles found in the textbook. The 
CSG presented the learners with 'problems' in a fictional global advertising, marketing and public relations firm with corresponding sets of solutions. Students were required to form teams and act as board directors to discuss the options. Students were also required to reflect on their personal experience in the board meetings. In order to ensure that learners would earnestly participate, their final grades were partly dependent (i.e. 5\%) on the final share price of the virtual company. Survey questionnaires were distributed to the students after all six weeks were completed. A drop-box was provided to students to return the questionnaires anonymously. Any halo effect from completing game-playing would have been negated by the fact that the end of game-playing did not signify the end of the course as students still had plenty to do after in completing their final assignment. In addition, although there were students who did well in gaining a high share price, many students also did poorly and mediocrely.

\section{Measures}

Bell and Federman (2010) assert that self-assessments are an appropriate form of measure for learning, with universities frequently using students' self-assessments to successfully inform and improve courses (Richardson, Maeda, and Swan 2010). The measures used in this study are affective measures as they are essentially about how learners felt about their experience to various parts of the curriculum (Armstrong and Fukami 2010, Moskal 2010, Bedggood and Donovan 2012). Mazer (2013b) argues that affective learning measures emphasise the process of learning, as opposed to cognitive learning measures that assesses the product of learning. Bedggood and Donovan (2012) found that most affect-based measures are instrumental in learning and can be classified into four distinct dimensions; i) perceived increase in knowledge and cognitive gains, ii) engagement, stimulation and motivation, iii) self-awareness of complexity and difficulty, and iv) self-evaluation of skills and performance. The development of the items were informed by student feedback from the previous year's run (which is very similar to this study) and by Bedggood and Donovan's (2012) affective dimension in learning. 
The items made references to specific parts of the course to help participants' recollection of their experiences (over the whole academic year) and the variety of activities undertaken. This approach is supported by research findings that have found measures adapted to its context have enhanced validity (e.g. Renaud and Murray, 2008) (in Appendix 1). The 'board meetings' presented a suitable opportunity for students to develop the cognitive skills as these sessions required students to solve the problems presented in scenarios by making sound decisions (e.g. trade-offs) based upon critical thinking and application of strategic management concepts. The lectures, seminars and portfolio work were primary mediums to increase students' knowledge. Students were required to reflect about the decision making process and their experiences when documenting each board meeting that occurred once a week. The CSG was used to induce positive emotions. Each set of items are designed to reflect of a common factor i.e. reflective measures (Podsakoff et al. 2005).

The risk that positive emotions may skew the self-assessment of the learning associated with them was mitigated by the order of the items within the survey questionnaire. The items related to the CSG and emotions were the last set of items in the questionnaire and this may help mitigate any halo effects from the positive assessment of game-playing with the other items. In addition, the survey questionnaire was distributed after six weeks of game-playing, in which students engaged with the CSG at least once a week. This extended game-playing process may also help to mitigate the effects of mood states that may have been more likely if the simulation game were only played once.

\section{Participants}

Data was obtained from 161 participants. The mean age of the participants was 21.9 years (SD $=2.3$ years) and 55.6 per cent were male. The average duration of work experience was 3.6 years (SD = 3.2). In terms of the learners' entry into the three-year long programme 55.3 per cent started in the 
first year, whilst 7.3 and 37.4 per cent started in the second and third year respectively. Concerning country of origin, 51.3 per cent were from the UK, 37.7 per cent were from China and the rest from various other countries. The proportion between those in team lead roles (i.e. chairperson) compared to those in ordinary members roles as board of directors were 22.4 to 77.6 percent respectively.

\section{Results}

Prior to testing the hypotheses, a principal components analysis was undertaken on the items used to measure cognitive skill, knowledge reflection and emotion. A five-component varimax with Kaiser Normalization solution with a cut-off value of 0.6 for item loadings was used. All items loaded. The results are provided in Table I. The Cronbach alpha of the items meets the minimum cut-off point recommended by Nunnally and Bernstein (1994) of .7 for newly developed scales (Lance, Butts, and Michels 2006). The averages score of the items were used to create overall scores for each of the four variables.

Table 1: Rotated solution for overall principal components analysis

\begin{tabular}{|c|c|c|c|c|c|}
\hline \multirow[t]{2}{*}{ Cronbach alpha } & \multirow[t]{2}{*}{ Construct } & \multicolumn{4}{|c|}{ Component } \\
\hline & & 1 & 2 & 3 & 4 \\
\hline \multirow[t]{3}{*}{$\alpha=.88$} & CogSkills1 & .884 & & & \\
\hline & CogSkills2 & .741 & & & \\
\hline & CogSkills3 & .693 & & & \\
\hline \multirow[t]{3}{*}{$\alpha=.71$} & Know1 & & & & .771 \\
\hline & Know2 & & & & .749 \\
\hline & Know3 & & & & .720 \\
\hline \multirow[t]{3}{*}{$\alpha=.83$} & Reflect1 & & & .758 & \\
\hline & Reflect2 & & & .647 & \\
\hline & Reflect3 & & & .645 & \\
\hline \multirow[t]{3}{*}{$\alpha=.78$} & Emotion1 & & .832 & & \\
\hline & Emotion 2 & & .808 & & \\
\hline & Emotion 3 & & .754 & & \\
\hline
\end{tabular}

Notes: Loadings above 0.60 are shown. CogSkills $=$ cognitive skills, Know $=$ knowledge, Reflect $=$ reflection, Emotion = emotions 
Table 2 contains the means, standard deviations and correlations of the measured variables. Cognitive skills, knowledge, reflection and emotions are significantly correlated with one another. The effects of age, gender, work experience, time of commencement at university, nationality and the learner's role in the teams on cognitive skills, knowledge, reflection and emotions were controlled. The controlled versions of these variables were used in the further analysis. 
Table 2: Means, standard deviations (SD) and correlations for the measured variables

\begin{tabular}{|c|c|c|c|c|c|c|c|c|c|c|c|}
\hline & Mean & $S D$ & 1 & 2 & 3 & 4 & 5 & 6 & 7 & 8 & 9 \\
\hline Age & 21.9 & 2.3 & - & & & & & & & & \\
\hline Gender & - & - & -0.00 & - & & & & & & & \\
\hline WorkExperience & 3.6 & 3.3 & $0.61 * *$ & 0.12 & - & & & & & & \\
\hline StartatUni & - & - & 0.57 & $-0.24 * *$ & $-0.20 *$ & - & & & & & \\
\hline Nationality & - & - & 0.10 & -0.07 & -0.11 & 0.10 & - & & & & \\
\hline Role & - & - & 0.54 & 0.09 & -0.71 & 0.06 & -0.02 & - & & & \\
\hline CogSkills & 4.0 & 0.6 & -0.27 & $0.25^{* *}$ & 0.01 & 0.14 & 0.02 & -0.03 & - & & \\
\hline Know & 4.0 & 0.6 & $0.16^{*}$ & 0.09 & $0.20 *$ & 0.08 & 0.04 & $-0.17 *$ & $0.40 * *$ & - & \\
\hline 9. Reflect & 3.9 & 0.7 & -.05 & $0.18^{*}$ & 0.78 & -0.09 & -0.03 & -0.16 & $0.32 * *$ & $0.46 * *$ & - \\
\hline 10. Emotion & 4.2 & 0.7 & 0.04 & -0.06 & 0.13 & $-0.18 *$ & 0.08 & -0.15 & $0.45 * *$ & $0.31 * *$ & $0.48 * *$ \\
\hline
\end{tabular}

Notes: ${ }^{*} p<0.05$ level, ${ }^{* *} p<0.01$. Gender: Male $=1$, Female $=2$. StartatUni: Started in Year $1=1$, Started in Year $2=2$, Started in Year $3=3$. Nationality: UK $=1$, China $=2$, Cayman Island = 3, Cyprus = 4, France $=5$, Hong Kong SAR = 6, India = 7, Indonesia = 8, Italy = 9, Portugal = 10, Russia = 11, Sweden = 12, Switzerland = 13, Thailand = 13, The Gambia $=15$, United Arab Emirates $=16$, United States of America $=17$, Poland $=18$. Role: Group Lead $=1$, Member $=$ 2.

Table 3: Results for the multiple linear regression analysis on cognitive skills

\begin{tabular}{lll} 
Predictors & $b$ & \\
\hline Knowz & 0.01 \\
Reflectz & 0.02 \\
Emotionz & 0.12 \\
KnowzxEmotionz & $0.26^{*}$ \\
ReflectzxEmotionz & 0.10 \\
\hline
\end{tabular}

Notes: ${ }^{*} p<0.05,{ }^{* *} p<0.01$. Know=knowledge standardised, Reflect=reflection standardised, Emotion=emotion standardised 
In testing the hypotheses, a multivariate linear regression was conducted, with knowledge, reflection and emotions used to predict cognitive skills. The standardised version of the constituent variable was used to calculate the product-term in reducing multicollinearity that is high correlation amongst the variables due to common source bias (rather than the constructs themselves). The results are presented in Table 3, which shows that emotion moderates the relationship between knowledge and cognitive skills. To more closely examine the moderation effects of emotion, the variable was divided into two groups of 'low' and 'high' using a median split. Next, a Spearman's product-moment analysis was used on the relationship between knowledge and cognitive skills for both groups of emotions. The correlation analyses revealed that the correlation between knowledge and cognitive skills was considerably larger for the high positive emotion group $(r=.32, p<.01)$ than for the low positive emotion group $(r=.25, p<.05)$. The direct effect of knowledge on cognitive skills is thus moderated by emotions. Hypothesis 1 is therefore supported. In addition a second Spearman's product-moment correlation analysis revealed that the correlation between reflection and cognitive skills was considerably larger for the high positive emotion group $(r=.23, p<.01)$ than for the low positive emotion group $(r=.14, p<.05)$. The indirect effect of knowledge on cognitive skills via reflection is thus moderated by affective trust in colleagues. Hypothesis 2 is therefore supported.

\section{Discussion}

Part of the findings in support of $\mathrm{H} 1$ suggests that knowledge is correlated with cognitive skills. This may be because knowledge involving the comprehension of the principles (Rittle-Johnson and Alibali 1999), provide the 'tools' for the student to evaluate new knowledge. Gaining new conceptual and procedural knowledge arises from students' active (re)construction of their mental schemas and by integrating new knowledge with prior knowledge (von Glasersfeld 1995). The ability to evaluate information inherently involves the expansion of knowledge. Individuals will enhance their ability to 
evaluate as their knowledge increases due to the varied perspective that they gain. This notion is supported by Hallett, Nunes, and Bryant (2010), as they assert that conceptual knowledge involves knowledge rich in relationships as it involves the linking and interweaving amongst discrete information and knowledge (Kieren 1993).

Lovett and Pillow (1996) state that the development of cognitive skills is a natural by-product of gaining knowledge because individuals must evaluate new knowledge prior to integrating it into their existing mental schemas. However, this notion may only be valid to a certain level as higher levels of cognitive skills require specific development (and not just more knowledge) (Facione 2006). In addition, students who are more knowledgeable may be more motivated, and thus be more willing to take on challenging situations that further develop their cognitive skills (Fyfe, RittleJohnson, and DeCaro 2012). The support for H1 may be due to positive emotions enhancing learners' intrinsic motivation to absorb knowledge and to better apply themselves to gain better understanding (D'Mello 2013).

The findings that support $\mathrm{H} 2$ suggest that reflection may enhance cognitive skills as the former helps learners to be more aware. Moon (1999) states that the steps that learners go through when learning from experience are 'noticing', 'making sense', 'making meaning' and 'working with meaning'. This shows that learning in higher education is multidimensional as it involves cognition, emotions and as well as action (e.g. 'doing') (Jackson and Chapman 2012). The interaction effect between reflection and emotion, and its impact on cognitive skills, for example, contribute to the broaden-and-build theory that argues "positive emotions appear to broaden people's momentary thought-action repertoires and build their enduring personal resources" (Fredrickson, 2004, p. 1369). Positive emotions help to develop learners' skills in a more enduring manner. However, extreme emotions, either positive or negative, are likely to impede rationality, objectivity and clarity of thought. Emotions are most advantageous when they are tempered and balanced. 
Students learn best when they are interested and engaged (Boyatzis, Stubbs, and Taylor 2002), and hence understanding and being able to shape students' affective states is crucial. Positive emotions are associated with engagement and intrinsic motivation (D'Mello 2013), whilst negative emotions are associated with task avoidance and ennui (Pekrun, Elliot, and Maier 2006). Trigwell, Ellis, and Han (2012) found that learners who experienced a higher level of positive emotions than negative emotions are more likely to adopt a deeper approach to learning, and thus improve cognitive gains. This notion is supported by Tallman and Gray (1990) who assert that problem solving refers to a series of decisions and involves not only cognitive components but also affective components. The findings has demonstrated that the classroom is a constellation of emotions (Goldman and Goodboy 2014) that impacts affective learning.

There are a number of implications, theoretically and in terms of practice. This study further supports our general understanding that emotions influence cognition (Brown 2000). Learners who are able to regulate their emotions (i.e. mitigate negative emotions) may also be more effective in learning. By being effective learners and adopting a variety of learning schemas and repertoire, these individuals may eventually be more succesful in life. The findings of the study further add credence to the notion that emotional intelligence (Goleman 1996) and intrapersonal intelligence (Gardner 1983) are crucial in predicting success in life.

In addition, the findings helps to further inform instructional theory (Horan, Martin, and Weber 2012). Possessing expertise in just the subject matter is insufficient as instructors should have broader competencies (Rooij 2013) that are informed by, for example, affective learning and should be able to incorporate this into a curriculum's instructional design. The CSG used in this study was a vehicle to evoke positive emotions, however, other teaching methods can also be used. Many scholars e.g. Doh (2009) and Salas, Wildman, and Piccolo (2009) argue that there is the need to 
integrate the use of CSG (and other novel learning materials, content and platforms such as virtual worlds) within the overall curriculum. Although this does take considerable time and effort in the initial stages, its use is flexible and pays off quickly. The course that was used for this study employed a CSG. The CSG did not only enable students to apply knowledge they had gained from the traditional pedagogic approach of lectures and seminars, but it was also used as a vehicle for student role playing activities, i.e. as a point of discussion and debate as students worked in groups. The experiential nature of game playing also stimulates sustained (over a longer period rather than in just one class or instance) positive emotions (i.e. interest) whilst learning.

Looking further afield, the findings demonstrate, alongside other research, that learning is a result of a convergence of interconnected factors (e.g. cognition, affect states and psychomotor) (Ward and Shortt 2013). This is not surprising as emotions are as important as intellectual aspects in university life (Denovan and Macaskill 2013) and thus in recognition of this there is a trend towards adopting a confluent learning approach that blends cognitive and affective domains in management education (Ward and Shortt 2013). Adopting a confluent learning approach is not only crucial for effective learning but also in developing learners holistically. Confluent learning can be achieved by presenting content in a stimulating manner, providing learners with opportunities to apply knowledge and practice what has been learned, and offering students with 'space and time' and the scaffolding to reflect on learning and experiences.

\section{Conclusion}

A key challenge for instructors is teaching the masses efficiently and effectively (Mottet et al. 2007). This study has made a small contribution in helping us to further understand how instructors can address the challenge of the diminishing 'human touch' in the classroom. The adoption and use of CSG, as an example, influence students' affective learning and thus help to increase students' satisfaction with their own learning. The CSG may directly and indirectly evoke emotions. CSG may 
do so directly by instigating both excitement and apprehension in students due to their anticipation of what the game may offer in the next stage. CSG may also indirectly stimulate affects such as a sense of camaraderie or competitiveness amongst students who may be collaborating in addressing the challenges as part of the games playing process. Classic methods such as lectures are efficient and can be made more effective with additional methods that help to evoke positive emotions.

Technology is usually touted as a key ally in addressing the challenges of managing large classes more efficiently and in minimising the effects of large tutor-student ratios that result in temporal and spatial distance. The use of technology is also crucial as many scholars, e.g., Fortmüller (2009), Walz and Schoch (2007) and Aldrich (2005), argue that it helps to meet expectations of the new generation of digital natives. CSG is an exemplar technology that helps students to learn by allowing them to apply concepts while game playing. Students' progress in game playing and attainment can also be recorded and tracked by tutors in helping managing large classes. In addition, some CSGs allow for both synchronous and asynchronous communication, and person-to-person interaction amongst students and tutors. Indeed, the opportunities that CSG provides to students to collaborate with one another helps to enhance the 'human touch' in learning and teaching. Given its benefits, it is no surprise that CSG has grown increasingly popular as a learning tool. The specific use of CSG and other technologies integrated with traditional teaching methods, better known as blended learning (Stubbs, Martin, and Endlar 2006), helps to create a stimulating environment that engages leaners' senses.

When viewing learning from a personal development perspective, one needs to recognise the importance of affective dimensions in learning. This view of learning acknowledges that learners have different individual starting points. This study has supported the views of other scholars that learning is an emotional process and has made a contribution to our understanding of the central 
and moderating role of emotions. In addition, this study helps further our understanding of the potential relationship between affective states in learning using new technologies (D'Mello 2013).

Nonetheless, as with all studies this research also have limitations. This study adopted just one perspective of affective states. Affective states are highly situational and may vary due to factors such as socialised dispositions (e.g. motivation) and other contextual factors and are usually symptoms of underlying causes such as lack of knowledge (Goetz et al. 2006). The affective view of learning also has its limitations. Learners generally respond with resistance as new knowledge usually challenges their autonomy. University is a challenging environment that students do not always find satisfying and learners are not always happy when they have to learn (Armstrong and Fukami 2010). These affective states may distort (as well as enhance) the real learning gains that learners may have made. In addition, whilst the use of affect measures are part of this study's aim, self-evaluations are inherently susceptible to bias. For instance, emotions influence the selfevaluation of cognitive skills and, in some cases, this may lead to overestimating one's own ability, which then produces sense of illusory superiority (Dunning et al. 2003). The 'sources' of learning may also be confounded between the intended method and the actual delivery (i.e. implementation) by the instructor.

Future research may address some of these limitations as well as build upon some of our understanding gained from this study. For example, future research may explore how reflection helps to develop metacognition. In addition, scholars may further investigate the dual role that emotions play in reflection; as the subject of reflection and as an input to reflection. Scholars may also investigate the impact of emotions in its role in the transfer of learning and the durability of learning using a longitudinal research design. Future research may explore how learner differences (e.g. dispositions, current knowledge and learning strategies) impact affective states in learning. Future research may study how cognitive skills and tacit, and procedural knowledge interact and/ or 
Loon, M. \& Bell, R. (2018) The Moderating Effects of Emotions on Cognitive Skills, Journal of Further and Higher Education, 42(5), 694-707. doi 10.1080/0309877X.2017.1311992

reinforce one another. In addition, future research may also further investigate the role of the instructor in evoking learner affective states. 


\section{References}

Ackoff, R.L. 1993. "The art and sciences of mess management." In Managing Change, edited by C. Mabey and B. Mayon-White. London: PCP.

Ainley, M. 2008. "Interest: A significant thread binding cognition and affect in the regulation of learning." International Journal of Psychology 43:17-18.

Ainley, M., M. Corrigan, and N. Richardson. 2005. "Students, tasks, and emotions: Identifying the contribution of emotions to students' reading of popular culture and popular science texts." Learning and Instruction 15:433-447.

Aldrich, C. 2005. Learning by doing: A comprehensive guide to simulations, computer games, and pedagogy in e-learning and other educational experiences. USA: Wiley.

American Philosophical Association. 1990. Critical Thinking: A Statement of Expert Consensus for Purposes of Educational Assessment and Instruction. ERIC document ED 315-423.

Anderson, L.W., and D.R. Krathwohl, eds. 2001. A Taxonomy for Learning, Teaching, and Assessing: A Revision of Bloom's Taxonomy of Educational Objectives. New York: Longman.

Argyris, C., and D. Schon. 1996. Organizational Learning II. Reading, MA: Addison-Wesley.

Armstrong, S.J., and C.V. Fukami. 2010. "Self-assessment of knowledge: A cognitive learning or affective measure? Perspectives from the management learning and education community." Academy of Management Learning \& Education 9 (2):335-341.

Ashby, F.G., A.M. Isen, and A.U. Turken. 1999. "A neuropsychological theory of positive affect and its influence on cognition." Psychological Review 106:529-550.

Bateson, G. 1972. Steps to Ecology of Mind. London: Paladin.

Beard, C., S. Clegg, and K. Smith. 2007. "Acknowledging the affective in higher education." British Educational Research Journal 33 (2):235-252.

Bedggood, R.E., and J.D. Donovan. 2012. "University performance evaluations: What are we really measuring?" Studies in Higher Education 37 (7):825-842.

Bell, B.S., and J.E. Federman. 2010. "Self-assessments of knowledge: Where do we go from here?" Academy of Management Learning \& Education 9 (2):342-347.

Biggers, T., and O.F. Rankis. 1983. "Dominance-submissiveness as an effective response to situations and as a predictor of approach-avoidance." Social Behavior and Personality 11:61-69. doi: http://dx.doi.org/10.2224/sbp.1983.11.2.61.

Boyatzis, R.E., E.C. Stubbs, and S.N. Taylor. 2002. "Learning cognitive and emotional intelligence competencies through graduate management education." Academy of Management Learning and Education 1 (2):150-162.

Brown, R.B. 2000. "Contemplating the emotional component of learning: The emotions and feelings involved when undertaking an MBA." Management Learning 31 (3):275-293.

Bruner, J. 1957. "Going beyond the information given." In Contemporary Approaches to Cognition, edited by J.S. Bruner, 41-69. Cambridge, MA: Harvard University Press.

Byrnes, J.P. 1992. "The conceptual basis of procedural learning." Cognitive Development 7:235-237.

Carroll, J.B. 1993. Human Cognitive Abilities. A Survey of Factor-Analytic Studies. Cambridge, UK: Cambridge University Press. 
Csikszentmihalyi, M. 1990. Flow: The Psychology of Optimal Experience. New York, NY: Harper and Row.

Culpin, V., and H. Scott. 2012. "The effectiveness of a live case study approach: Increasing knowledge and understanding of 'hard'versus 'soft'skills in executive education." Management Learning 43 (5):565 -577.

D'Mello, S. 2013. "A selective meta-analysis on the relative incidence of discrete affective states during learning with technology." Journal of Educational Psychology 105 (4):1082-1099.

D'Mello, S., and A. Graesser. 2011. "The half-life of cognitive-affective states during complex learning." Cognition \& Emotion 25:1299-1308.

Denovan, A., and A. Macaskill. 2013. "An interpretative phenomenological analysis of stress and coping in first year undergraduates." British Educational Research Journal 39 (6):1002-1024.

Dewey, J. 1933. How We Think: A Restatement of the Relation of Reflective Thinking to the Education Process. Boston: D. C. Health.

DeYoung, C.G. , J.L. Flanders, and J.B. Peterson. 2008. "Cognitive abilities involved in insight problem solving: An individual differences model." Creativity Research Journal 20 (3):278-290.

Doh, J.P. 2009. "Introduction: The real world via simulation." Academy of Management Learning \& Education 8 (4):558.

Dunning, D., K. Johnson, J. Ehrlinger, and J. Kruger. 2003. "Why people fail to recognize their own incompetence." Current Directions in Psychological Science 12 (3):83-87.

Ekman, P. 1992. "An argument for basic emotions." Cognition \& Emotion 6 (3-4):169-200.

Facione, P.A. 2006. Critical Thinking: What It Is and Why it Counts. Millbrae, CA: Insight Assessment.

Fortmüller, R. 2009. "Learning through business games: Acquiring competences within virtual realities." Simulation \& Gaming 40 (1):68-83.

Fredrickson, B.L. 2004. "The broaden-and-build theory of positive emotions." Philosophical Transactions of the Royal Society of London Series B: Biological Sciences 359:1367-1378. doi: 10.1098/rtsb.2004.1512.

Frensch, .PA., and J. Funke. 2002. Thinking and problem solving. In Psychology, from Encyclopedia of Life Support Systems (EOLSS), Developed under the Auspices of the UNESCO, , edited by N. Cowan. Oxford ,UK: Eolss Publishers.

Fyfe, E.R., B. Rittle-Johnson, and M.S. DeCaro. 2012. "The effects of feedback during exploratory mathematics problem solving: Prior knowledge matters." Journal of Educational Psychology 104 (4):1094-1108.

Gardner, H. 1983. Frames of Mind: The Theory of Multiple Intelligences. New York: Basic Books.

Georghiades, P. 2000. "Beyond conceptual change learning in science education: focusing on transfer, durability and metacognition." Educational Research 42 (2):119-139.

Giancarlo, C.A., and P.A. Facione. 2001. "A look across four years at the disposition toward critical thinking among undergraduate students." The Journal of General Education 50 (1):29-55.

Goetz, T., R. Pekrun, N. Hall, and L. Haag. 2006. "Academic emotions from a social-cognitive perspective: Antecedents and domain specificity of students' affect in the context of Latin instruction." British Journal of Educational Psychology 76:289-308.

Goldman, Z.W., and A.K. Goodboy. 2014. "Making students feel better: Examining the relationships between teacher confirmation and college students' emotional outcomes." Communication Education 63 (3):259-277. 
Goleman, D. 1996. Emotional Intelligence: Why it can Matter more than IQ. London: Bloomsbury.

Hallett, D., T. Nunes, and P. Bryant. 2010. "Individual differences in conceptual and procedural knowledge when learning fractions." Journal of Educational Psychology 102 (2):395-406.

Harmon-Jones, E., C. Harmon-Jones, D.M. Amodio, and P.A. Gable. 2011. "Attitudes toward emotions." Journal of Personality and Social Psychology 101 (6):1332-1350.

Hénard, F., and S. Leprince-Ringuet. 2008. The Path to Quality Teaching in Higher Education. Paris: Organisation for Economic Cooperation and Development.

Hénard, F., and D. Roseveare. 2012. Fostering quality teaching in higher education: Policies and practices. In Institutional Management in Higher Education. Paris: Organisation for Economic Cooperation and Development.

Hinett, K. 2002. Improving learning through reflection. The Higher Education Academy.

Horan, S.M., M.M. Martin, and K. Weber. 2012. "Understanding emotional response theory: The role of instructor power and justice messages." Communication Quarterly 60 (2):210-233.

Isen, A.M. 1999. "Positive affect." In Handbook of Cognition and Emotion, edited by T. Dalgleish and M. Power, 521-539. New York: Wiley.

Jackson, D., and E. Chapman. 2012. "Non-technical competencies in undergraduate business degree programs: Australian and UK perspectives." Studies in Higher Education 37 (5):541-567.

Jennings, P.A., and M.T. Greenberg. 2009. "The prosocial classroom: Teacher social and emotional competence in relation to student and classroom outcomes." Review of Educational Research 79 (1):491-525.

Keevers, L., and L. Treleaven. 2011. "Organizing practices of reflection: A practice-based study." Management Learning 42 (5):505-520.

Kember, D., J. Biggs, and D.Y. Leung. 2004. "Examining the multidimensionality of approaches to learning through the development of a revised version of the Learning Process Questionnaire." British Journal of Educational Psychology 74 (2):261-279.

Kieren, T.E. 1993. "Rational and fractional numbers: From quotient fields to recursive understanding." In Rational Numbers: An Integration of Research, edited by T.P. Carpenter, E. Fennema and T.A. Romberg, 49-84. Hillsdale, NJ: Erlbaum.

Knight, P.T. 2002. Being a Teacher in Higher Education. Buckingham, UK.: Open University Press. Lance, C.E., M.M. Butts, and L.C. Michels. 2006. "The sources of four commonly reported cutoff criteria: What did they really say?" Organizational Research Methods 9 (2):202-220.

Leijen, Ä., K. Valtna, D.A. Leijen, and M. Pedaste. 2012. "How to determine the quality of students' reflections?" Studies in Higher Education 37 (2):203-217.

Lovett, S.B., and B.H. Pillow. 1996. "Development of the ability to distinguish between comprehension and memory: Evidence from goal-state evaluation tasks." Journal of Educational Psychology 88 (3):546-562.

Mazer, J.P. 2013a. "Student emotional and cognitive interest as mediators of teacher communication behaviors and student engagement: An examination of direct and interaction effects." Communication Education 62 (3):253-277.

Mazer, J.P. 2013b. "Validity of the student interest and engagement scales: Associations with student learning outcomes." Communication Studies 64 (2):125-140.

Meinhardt, J., and R. Pekrun. 2003. "Attentional resource allocation to emotional events: An ERP study." Cognition and Emotion 17:477-500. 
Moon, J. 1999. Reflection in Learning and Professional Development: Theory and Practice London: Kogan Page.

Moskal, B.M. 2010. "Self-assessments: what are their valid uses?" Academy of Management Learning \& Education 9 (2):314-320.

Mottet, T.P., J. Parker-Raley, S.A. Beebe, and C. Cunningham. 2007. "Instructors who resist "college lite": The neutralizing effect of instructor immediacy on students' course-workload violations and perceptions of instructor credibility and affective learning." Communication Education 56 (2):145167.

Muijs, D., and G. Lindsay. 2008. "Where are we at? An empirical study of levels and methods of evaluating continuing professional development." British Educational Research Journal 34 (2):195211.

Nielsen, K. 2008. "Learning trajectories and reflection-in-practice through teaching." Reflective Practice 9 (4):485-495.

Nunnally, J.C., and I.H. Bernstein. 1994. Psychometric Theory. Sydney: McGraw-Hill.

Parnes, S.J. 1975. Aha! Insights into Creative Behavior. Buffalo, NY.: DOK.

Pedrosa-de-Jesus, H., and M. Watts. 2014. "Managing affect in learners' questions in undergraduate science." Studies in Higher Education 39 (1):102-116.

Pekrun, R., A.J. Elliot, and M.A. Maier. 2006. "Achievement goals and discrete achievement emotions: A theoretical model and prospective test." Journal of educational psychology, 98(3), 98 (3):583-597.

Pekrun, R., T. Goetz, W. Titz, and R.P. Perry. 2002. "Academic emotions in students' self-regulated learning and achievement: A program of qualitative and quantitative research." Educational Psychologist 37 (2):91-105.

Peterson, D.R. 1995. "The reflective educator." American Psychologist 50 (12):975-983.

Podsakoff, P.M., S.B. Mackenzie, D.G. Bachrach, and N.P. Podsakoff. 2005. "The influence of management journals in the 1980s and 1990s." Strategic Management Journal 26 (5):473-488. doi: 10.1002/smj.454.

Posner, J., J.A. Russell, and BS. Peterson. 2005. "The circumplex model of affect: An integrative approach to affective neuroscience, cognitive development, and psychopathology." Development and Psychopathology 17 (3):715-734.

Quesada, J., W. Kintsch, and E. Gomez. 2005. "Complex problem-solving: a field in search of a definition?" Theoretical Issues in Ergonomics Science 6 (1):5-33.

Raelin, J.A. 2007. "Toward an epistemology of practice." Academy of Management Learning and Education 6:495-519.

Rawson, M. 2000. "Learning to learn: More than a skill set." Studies in Higher Education 25 (2):225238.

Renaud, R.D., and H.G. Murray. 2008. "A comparison of a subject-specific and a general measure of critical thinking." Thinking Skills and Creativity 3 (2):85-93.

Richardson, J.C., Y. Maeda, and K. Swan. 2010. "Adding a web-based perspective to the selfassessment of knowledge: Compelling reasons to utilize affective measures of learning." Academy of Management Learning \& Education 9 (2):329-334.

Rittle-Johnson, B., and M.W. Alibali. 1999. "Conceptual and procedural knowledge of mathematics: Does one lead to the other? ." Journal of Educational Psychology 91:175-189. 
Rittle-Johnson, B., and J.R. Star. 2009. "Compared with what? The effects of different comparisons on conceptual knowledge and procedural flexibility for equation solving." Journal of Educational Psychology 101 (3):529-544.

Rogers, C.R. 1994. Freedom to Learn. New York: Merrill.

Rooij, S.W.V. 2013. "The career path to instructional design project management: an expert perspective from the US professional services sector." International Journal of Training and Development 17 (1):33-53.

Salas, E., J.L. Wildman, and R.F. Piccolo. 2009. "Using simulation-based training to enhance management education." Academy of Management Learning \& Education 8 (4):559-573.

Schiefele, U. 1991. "Interest, learning, and motivation." Educational Psychologist 26 (3-4):299-323.

Schimmack, U., and A. Grob. 2000. "Dimensional models of core affect: A quantitative comparison by means of structural equation modeling." European Journal of Personality 14 (4):325-345.

Schön, D. 1983. The Reflective Practitioner: How Professionals Think in Action. Boston: Arean Publishing.

Scott, S.G. 2010. "Enhancing reflection skills through learning portfolios: An empirical test." Journal of Management Education 34 (3):430-457.

Shepherd, D.A. 2004. "Educating entrepreneurship students about emotion and learning from failure." Academy of Management Learning \& Education 3 (3):274-287.

Shipton, H., and J. Sillince. 2012. "Organizational learning and emotion: constructing collective meaning in support of strategic themes." Management Learning 44 (5):493 -510.

Stubbs, M., I. Martin, and L. Endlar. 2006. "The structuration of blended learning: Putting holistic design principles into practice." British Journal of Educational Technology 37 (2):163-175.

Tallman, I., and L.N. Gray. 1990. "Choices, decisions, and problem-solving." Annual Review of Sociology 16 (1):405-433.

Trigwell, K., R.A. Ellis, and F. Han. 2012. "Relations between students' approaches to learning, experienced emotions and outcomes of learning." Studies in Higher Education 37 (7):811-824.

Van Lehn, K. 1996. "Cognitive skill acquisition." Annual Review of Psychology 47 (1):513-539.

Värlander, S. 2008. "The role of students' emotions in formal feedback situations." Teaching in Higher Education 13 (2):145-156.

Vertue, F.M., and B.D. Haig. 2008. "An abductive perspective on clinical reasoning and case formulation." Journal of Clinical Psychology 64 (9):1046-1068.

Vince, R. 2010. "Anxiety, politics and critical management education." British Journal of Management 21 (1):526-539.

von Glasersfeld, E. 1995. A Way of Knowing and Learning. London: Falmer Press.

Walz, S.P., and O. Schoch. 2007. "Pervasive game design as an architectural teaching and research method." In Games and simulations in online learning: Research and development frameworks, edited by D. Gibson, C. Aldrich and M. Prensky, 236-249. London: Information Science Publishing.

Ward, J., and H. Shortt. 2013. "Evaluation in management education: A visual approach to drawing out emotion in student learning." Management Learning 44 (5):435-452.

Wood Daudelin, M. 1997. " Learning from experience through reflection." Organizational Dynamics 24 (3):36-48. 
Zuckerman, G. 2004. "Development of reflection through learning activity." European Journal of Psychology of Education 19 (1):9-18.

Zundel, M. 2013. "Walking to learn: Rethinking reflection for management learning." Management Learning 44 (2):109-126. 


\section{Appendix 1}

\section{Measures}

\section{Cognitive Skills}

1. Participation in board meetings helped me to improve my;
a. decision-making skills
b. problem solving skills
c. critical thinking skills

Knowledge

2. The lectures/seminars and portfolio work;

a. provided me with a better breadth of understanding of business strategies,

b. reinforced my knowledge about developing business strategies,

c. increased the depth of my knowledge in business strategising

\section{Reflection}

3. In writing up the board meetings I am able to better reflect on the;
a. debates in the meetings,
b. decisions made, and
c. points of arguments in the meetings

Emotion

4. The simulation game made;
a. the module more interesting,
b. me appreciate the complexity of business strategies,
c. me more engaged in the module 